\title{
Effect of Alumina Nanoparticles on the Photoluminescence of Rh110 Laser Dye Doped with organically modified silicate (ORMOSIL)
}

\author{
Ahmed Namah Mohamed \\ Physics Department / Al- Muthanna/ science College/ Samawa/Iraq \\ Corresponding author:aljeashie@gmail.com \\ Received 2017/1/19, Accepted:14/3/2017, Published 33/4/2017
}

DOI: $10.52113 / 2 / 04.01 .2017 / 21-26$

\begin{abstract}
Alumina nanoparticles was synthesized using sol-gel technique and the structural characteristics of these nanoparticles were investigated using AFM where found the size of particles about $(80-100 \mathrm{~nm})$, and it has been studying the effect of these nanoparticles on photoluminescence (absorption and fluorescence) of Rh110 dye laser solution also doped it with non-organic media (ORMOSIL). FTIR analysis has been recorded to the final sample to investigate the vibrational mode of both the silica and the alumina bonds.
\end{abstract}

(C) 2017 Muthanna University. All rights reserved.

Keyword: Laser Dye, Sol-Gel Technique, Alumina Nanoparticles, Photoluminescence.

\section{Introduction:}

There are many techniques can be synthesized for $\mathrm{Al}_{2} \mathrm{O}_{3}$ nanoparticles including ball milling, sol-gel, pyrolysis, sputtering, hydrothermal, and laser ablation[1,2,3]. Sol-gel is one of the most successful techniques to fabricate high photocatalytic Alumina nanostructures [4].

Sol- gel method could get certain properties of heterogeneous materials are required, such as mechanical hardness, optical permeability, chemical stability, porosity required, and size appropriate [5].

Sol-gel, a commonly used technique, involves the formation of an amorphous gel from a precursor solution. This method based on molecular precursors usually makes use of metal alkoxides as raw material. Some advantages of the sol-gel method are better homogeneity and purity from raw material, lower preparation temperature which save energy cost and the ability to form unique composition [6].

\section{Experimental Part}

Alumina nanoparticles $\left(\mathrm{Al}_{2} \mathrm{O}_{3}\right)$ were prepared via sol-gel method using the precursor aluminum trichloride $\left(\mathrm{AlCl}_{3}\right)$ as the starting materials. $28 \%$ of ammonia was added slightly to stirred ethanolic solution of aluminum chloride
There are number of materials which have been used as solid hosts for laser dyes such as: polymers, porous glasses, organically modified silicates or silicate nanocomposites, and polycom glass (combination of polymer and sol-gel) [7].

A polymer was first reported as a medium for organic laser dye. Which many defects of polymer as host for laser dye such as low the rmoconductivity and laser damage threshold [8]. In contrast, sol-gel technology makes it possible to doping of organic dyes into inorganic matrices by low-temperature solution processing. The antiirradiating property, mechanical and chemical stability of inorganic matrices are better than those of organic matrices [9].

The purpose of the current work is using sol-gel method to synthesis of $\mathrm{Al}_{2} \mathrm{O}_{3}$ nanoparticles as scattering particles, and study the spectroscopic properties of these nanoparticles doped on silica matrix and organic compound (Rh110 laser dye).

$(0.1 \mathrm{M})$. The gel was let to maturate for 30 hours at room temperature. After filtering in vacuum system, drying at $100^{\circ} \mathrm{C}$ for $24 \mathrm{~h}$ in an oven, and annealing at $1000^{\circ} \mathrm{C}$.

Rhodamine 110 solution was prepared by dissolving $7.34 \times 10^{-4} \mathrm{gm}$ in $10 \mathrm{ml}$ of absolute 
ethanol and stirrer about 30 minutes to obtain homogenous solution of concentration $2 \times 10^{-4}$ $\mathrm{mol} / \mathrm{liter}$ then diluting to $1.5 \times 10^{-4}, 1 \times 10^{-4}$, $0.5 \times 10^{-4} \mathrm{~mol} / \mathrm{liter}$.

Silica gel (ORMOSIL) host samples doped with $\mathrm{Al}_{2} \mathrm{O}_{3}$ nanoparticles- $\mathrm{R} 110$ mixture were prepared as follows; TEOS and ethanol were mixed at molar ratio of 1:4 to prepare silica solution. The catalyst solution was contained deionized water of unity $\mathrm{pH}$ (using $0.15 \mathrm{M}$ of hydrochloric acid $\mathrm{HCl}$ ) mixed with ethanol at molar ratio of 2:4. Then $\mathrm{Al}_{2} \mathrm{O}_{3}$ nanoparticles- $\mathrm{R} 110$ mixture were added. The final sol was left stirrer for half hour. Finally, the final sample casting at $60^{\circ} \mathrm{C}$. The gel phase was obtained after a few days, and the drying process reaction temperature $90^{\circ} \mathrm{C}$ drying two hours.

Atomic force microscopy (AFM) was used to achieve the morphology of $\mathrm{Al}_{2} \mathrm{O}_{3}$ nanoparticles. Alumina film was made by preparing suspension as film by spin coating process.

The absorption spectra of the prepared samples were obtained using UV-VIS double beam spectrometer in the wave length range from 190 to $1100 \mathrm{~nm}$, while the fluorescence spectra were done using F96 spectrophotomer.

Results and discussion

In order to study the surface topography of the Alumina nanoparticles at the preparation conditions on it, atomic force microscope (AFM) was used as it has the ability to produce micrographs and analyze the surface of the samples under investigation to give very precious statistical values of average grain size and grains distribution as well as providing a lot of important information. Figure (1) shows the (AFM) micrographs of Alumina nanoparticles.
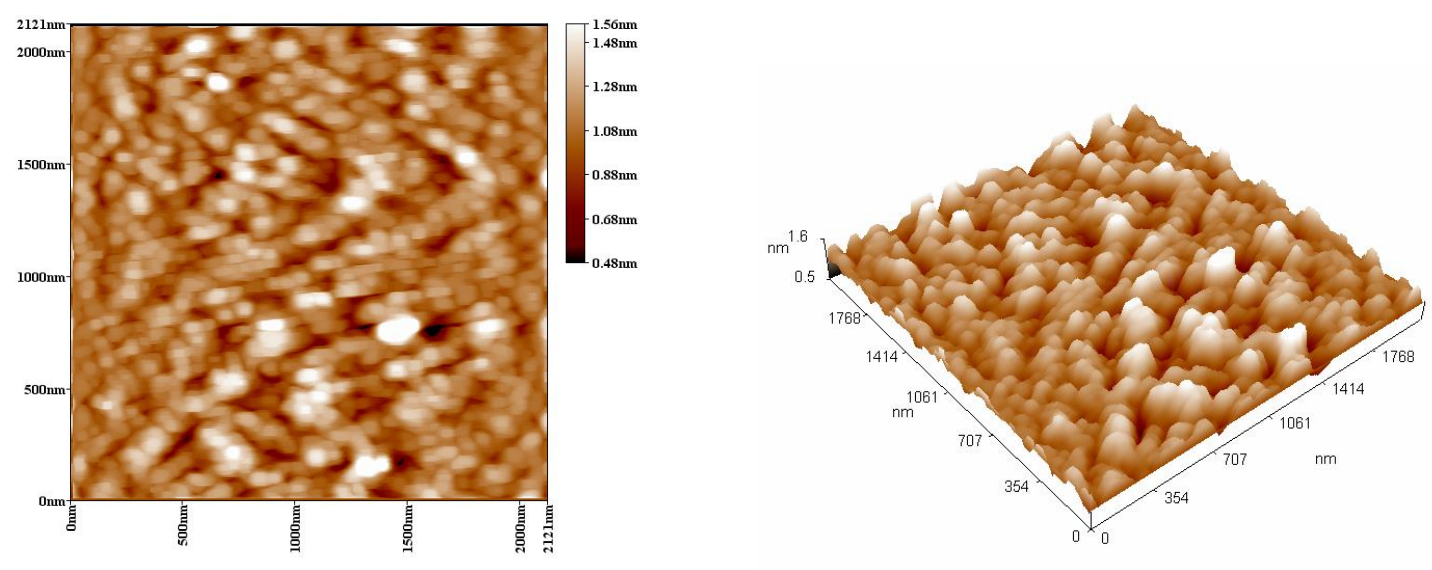

Figure (1): the (AFM) micrographs of Alumina nanoparticles. The FTIR spectrum of the composite $\mathrm{Al}_{2} \mathrm{O}_{3}$ and $\mathrm{SiO}_{2}$ shown in Figure (2)

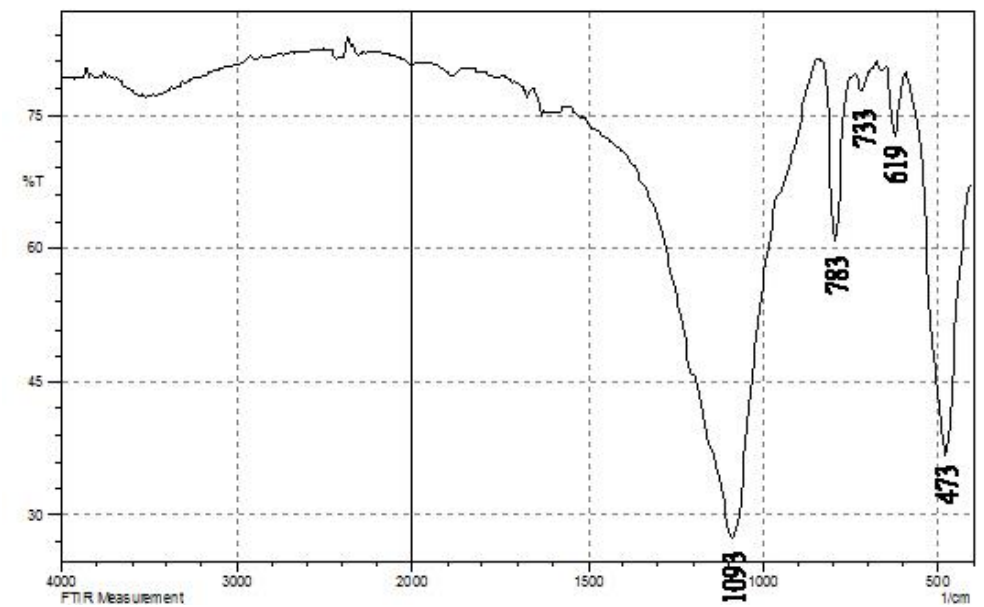

Figure(2): FTIR spectrum of the composite $\mathrm{Al}_{2} \mathrm{O}_{3}$ and $\mathrm{SiO}_{2}$ 
Figure (2) shows the peaks at the wave number of $1093 \mathrm{~cm}^{-1}, 473 \mathrm{~cm}^{-1}$ are caused by bending vibration of functional group of $\mathrm{Si}-\mathrm{O}$ [10]. The bands at $619 \mathrm{~cm}^{-1}, 783 \mathrm{~cm}^{-1}$ are ascribed to vibration modes of Al-O [11], and $733 \mathrm{~cm}^{-1}$ are attributed to the $\mathrm{Al}-\mathrm{O}$ mode of boehmite [12].

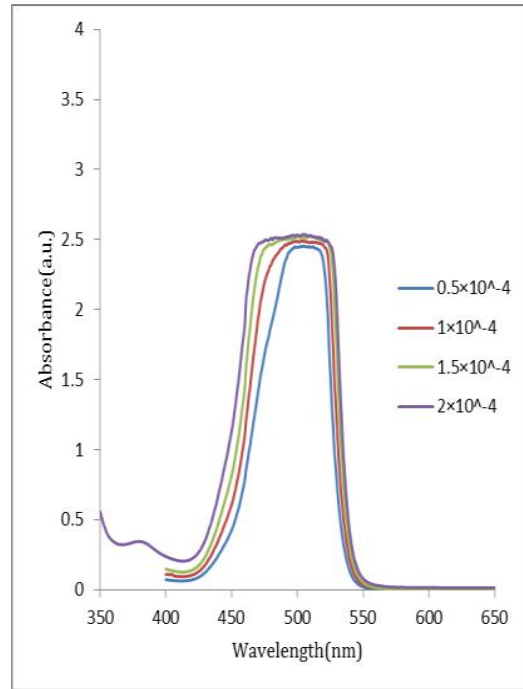

(a) Rh110 dye solution

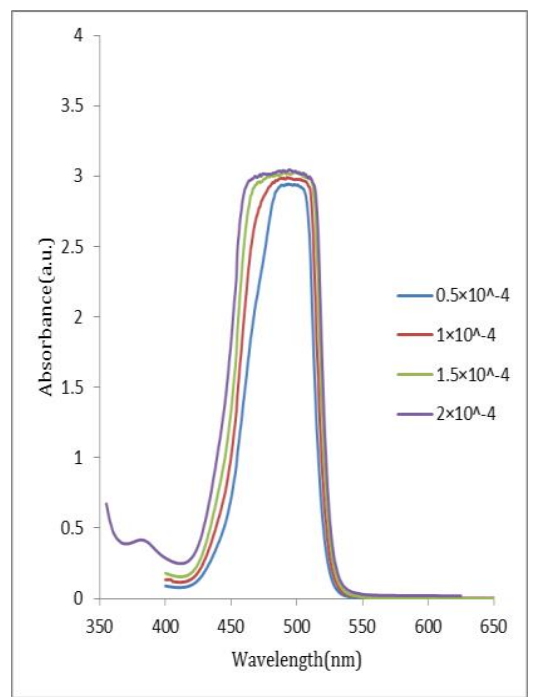

(b) $\mathrm{R} 110 / \mathrm{Al}_{2} \mathrm{O}_{3}$
Figure (3) shows the absorption spectra for dye solution at different concentrations dissolved in ethanol and mixture with $\mathrm{Al}_{2} \mathrm{O}_{3}$ and doped in silica gel. The maximum absorption intensity peak occurs at $505 \mathrm{~nm}$ of dye in ethanol solution at $2 \times 10^{-4} \mathrm{~mol} / \mathrm{lit}$.

\section{Figure (3): The absorption spectra for Rh110 dye solution dissolved in ethanol} and mixture with $\mathrm{Al}_{2} \mathrm{O}_{3}$ and doped in silica gel

It can be seen that, for the dye solutions, the intensity of absorption band is increased with increasing the dye concentration from $2 \times 10^{-4}$ to $0.5 \times 10^{-4} \mathrm{~mol} / \mathrm{liter}$ as shown in figure (3-a). This causes the blue shift in the absorption spectrum with $2 \times 10^{-4} \mathrm{~mol} /$ lit dye concentration.

In the case of dye mixed with $\mathrm{Al}_{2} \mathrm{O}_{3}$ nanoparticles samples, the absorption intensity at the peak of each band increased with increasing of dye concentration as shown in figure (3-b). This causes in the absorption spectrum due to the corresponding increase in the cross section area of the particle inside the sample where more absorption of light.

When the absorption spectra of $\mathrm{Al}_{2} \mathrm{O}_{3}$ Rh110 nanoparticles mixture doped in silica gel, the absorption intensity at the peak of each band increased with increasing of dye concentration as shown in figure (3-c). The reason of these shifts is due to increasing of dye concentration which causes increasing in the number of molecules in volume unit which leads to change in energy level of dye as result of increasing in perturbation field on the molecules, this agree with the explanation of Chen and Fox (1977) [13].

Table (1) shows the change of different parameters of absorbance with concentration of Rh110 dye solution in ethanol, $\mathrm{Rh} 110 / \mathrm{Al}_{2} \mathrm{O}_{3}$ mixture and $\mathrm{R} 110 / \mathrm{Al}_{2} \mathrm{O}_{3}$ doped with sol-gel wavelength corresponding to the maximum absorbance and full width at half maximum FWHM. 
Table (1): Rh110 dye solution in ethanol, $\mathrm{Rh} 110 / \mathrm{Al}_{2} \mathrm{O}_{3}$ mixture and $\mathrm{R} 110 / \mathrm{Al}_{2} \mathrm{O}_{3}$ doped with sol-gel different parameters of absorbance

\begin{tabular}{|c|c|c|c|c|c|c|c|c|c|}
\hline \multirow{2}{*}{$\begin{array}{c}\text { Concentration } \\
\text { mol/lite }\end{array}$} & \multicolumn{3}{|c|}{ Rh110 dye solution } & \multicolumn{4}{c|}{$\mathrm{R} 110 / \mathrm{Al}_{2} \mathrm{O}_{3}$} & \multicolumn{3}{c|}{$\begin{array}{c}\text { silica gel doped with } \\
\text { R110/Al } \mathrm{O}_{3}\end{array}$} \\
\cline { 2 - 10 } & $\begin{array}{c}\text { Max. } \\
\text { Abs. }\end{array}$ & $\begin{array}{c}\lambda \\
(\mathrm{nm})\end{array}$ & $\begin{array}{c}\text { FWHM } \\
(\mathrm{nm})\end{array}$ & $\begin{array}{c}\text { Max. } \\
\text { Abs. }\end{array}$ & $\begin{array}{c}\lambda \\
(\mathrm{nm})\end{array}$ & $\begin{array}{c}\text { FWHM } \\
(\mathrm{nm})\end{array}$ & $\begin{array}{c}\text { Max. } \\
\text { Abs. }\end{array}$ & $\begin{array}{c}\lambda \\
(\mathrm{nm})\end{array}$ & $\begin{array}{c}\text { FWHM } \\
(\mathrm{nm})\end{array}$ \\
\hline $0.5 \times 10^{-4}$ & $\mathbf{2 . 4 5 5}$ & $\mathbf{5 0 4}$ & 60 & 2.943 & 491 & 53 & 3.535 & 483 & 47 \\
\hline $1 \times 10^{-4}$ & 2.493 & 503 & 72 & 2.99 & 492 & 62 & 3.590 & 482 & 56 \\
\hline $1.5 \times 10^{-4}$ & 2.524 & 500 & 79 & 3.035 & 490 & 69 & 3.642 & 480 & 61 \\
\hline $2 \times 10^{-4}$ & 2.538 & 505 & 86 & 3.047 & 494 & 75 & 3.656 & 483 & 67 \\
\hline
\end{tabular}

Figure (4): shows the fluorescence spectra for dye solution at different concentrations dissolved in ethanol and mixture with $\mathrm{Al}_{2} \mathrm{O}_{3}$ and doped in silica gel.

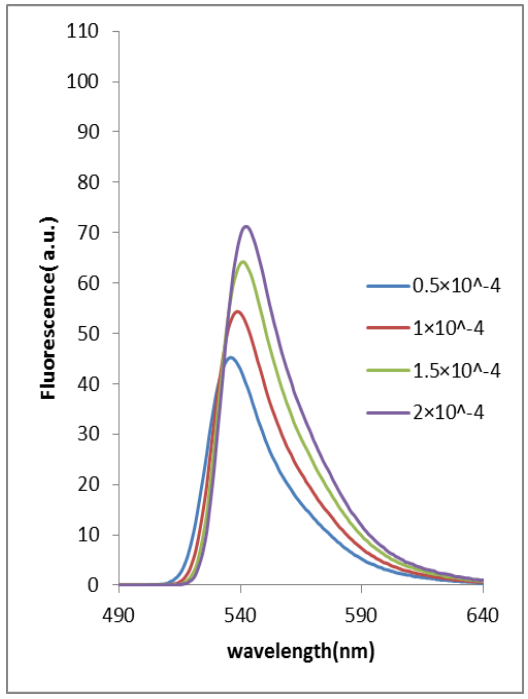

Rh110 dye solution

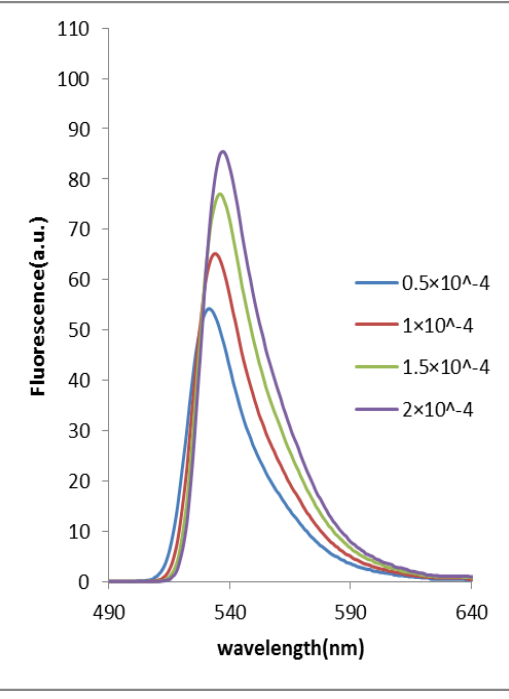

$\mathrm{R110} / \mathrm{Al}_{2} \mathrm{O}_{3}$

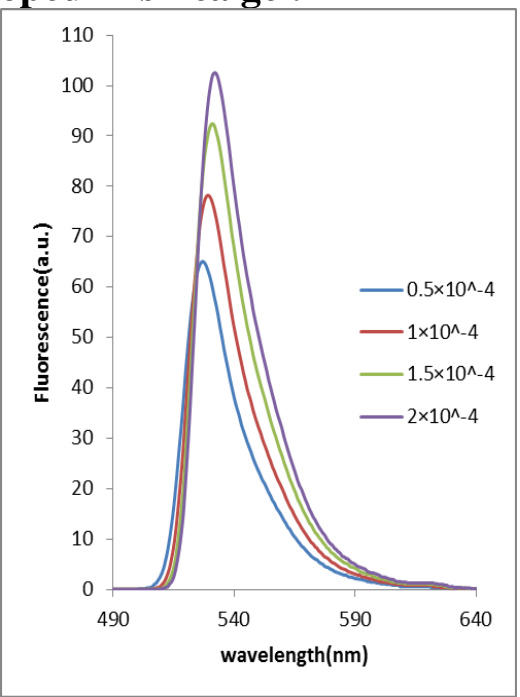

silica gel doped with $\mathrm{R110}_{/} \mathrm{Al}_{2} \mathrm{O}_{3}$

Figure (4): The fluorescence spectra for Rh110 dye solution dissolved in ethanol and mixture with $\mathrm{Al}_{2} \mathrm{O}_{3}$ and doped in silica gel

From figure (4-a), for the dye solutions, the intensity of the fluorescence have a maximum value at $2 \times 10^{-4} \mathrm{~mol} / \mathrm{lit}$ dye concentration at $542 \mathrm{~nm}$. Higher concentrations give the lower fluorescence intensity, which may attributed to the concentration quenching process that becomes more active at high concentration levels.

By comparing figures (4-a) and (4-b), it is obvious that the spectral broadening for the Rh110 dye solution is higher in magnitude than that in silica gel matrix. While when one compare figures (4-a,b) with (4-c), it could be notices that the fluorescence intensity in case of silica gel doped with $\mathrm{R} 110-\mathrm{Al}_{2} \mathrm{O}_{3}$ nanoparticles more intense than the case (a) and (b). This could attribute to the random unconstrained motion of the liquid molecules which is larger than that of the solid molecules. This results in a dissipation of energy due to molecules collisions indicating that the broadening mechanism is homogeneous in type. Since the inter - molecular distance in the solid is small, the collisions between molecules are so rare and thus, no noticeable energy loss is observed, which coincided with the results of Antony Streeter in 2002 [14].

Table (2) shows the change of different parameters of fluorescence with concentration of Rh110 dye solution in ethanol, $\mathrm{Rh} 110 / \mathrm{Al}_{2} \mathrm{O}_{3}$ 
mixture and $\mathrm{R} 110 / \mathrm{Al}_{2} \mathrm{O}_{3}$ doped with sol-gel wavelength corresponding to the maximum fluorescence and full width at half maximum FWHM.

Table (2) $\mathrm{Rh} 110$ dye solution in ethanol, $\mathrm{Rh} 110 / \mathrm{Al}_{2} \mathrm{O}_{3}$ mixture and $\mathrm{R} 110 / \mathrm{Al}_{2} \mathrm{O}_{3}$ doped with sol-gel different parameters of fluorescence

\begin{tabular}{|c|c|c|c|c|c|c|c|c|c|}
\hline \multirow{2}{*}{$\begin{array}{c}\text { Concentration } \\
\text { mol/lite }\end{array}$} & \multicolumn{3}{|c|}{ Rh110 dye solution } & \multicolumn{3}{|c|}{$\mathrm{R} 110 / \mathrm{Al}_{2} \mathrm{O}_{3}$} & \multicolumn{3}{|c|}{$\begin{array}{l}\text { silica gel doped with } \\
\mathrm{R} 110 / \mathrm{Al}_{2} \mathrm{O}_{3}\end{array}$} \\
\hline & $\begin{array}{l}\text { Max. } \\
\text { Flu. }\end{array}$ & $\underset{(\mathbf{n m})}{\lambda}$ & $\begin{array}{c}\text { FWHM } \\
(\mathbf{n m})\end{array}$ & $\begin{array}{l}\text { Max. } \\
\text { Flu. }\end{array}$ & $\begin{array}{c}\lambda \\
(\mathbf{n m})\end{array}$ & $\begin{array}{c}\text { FWHM } \\
(\mathbf{n m})\end{array}$ & $\begin{array}{l}\text { Max. } \\
\text { Flu. }\end{array}$ & $\begin{array}{c}\lambda \\
(\mathbf{n m})\end{array}$ & $\begin{array}{c}\text { FWHM } \\
(\mathbf{n m})\end{array}$ \\
\hline $0.5 \times 10^{-4}$ & 45.2 & 536 & 31 & 54.2 & 531 & 28 & 65 & 527 & 24 \\
\hline $1 \times 10^{-4}$ & 54.3 & 539 & 32 & 64.1 & 534 & 30 & 78.1 & 529 & 26 \\
\hline $1.5 \times 10^{-4}$ & 64.2 & 541 & 33 & 77 & 536 & 31 & 92.4 & 531 & 27 \\
\hline $2 \times 10^{-4}$ & 71.2 & 542 & 34 & 85.4 & 537 & 33 & 102.5 & 532 & 28 \\
\hline
\end{tabular}

\section{Conclusions}

In summary alumina nanoparticles were synthesized using sol-gel method. The morphology of these particles was investigate using AFM technique and the effect of these particles is clear on the photoluminescence of

\section{Reference}

[1] C.B. Reid, J.S. Forrester, H.J. Goodshaw, E.H. Kisi, G.J. Suaning, "A study in the mechanical milling of alumina powder", Ceramics Int. 34 (2008) 1551- 1556.

[2] F. Mirjalili, M. Hasmaliza, C. Abdullah, "Size-controlled synthesis of nano $\alpha$-alumina particles through the sol-gel method" Ceramics Int. 36 (2010) 1253- 1257.

[3] D.H. Trinh, M. Ottosson, M. Collin, I. Reineck, L. Hultman, H. Högberg, "Nanocomposite $\mathrm{Al}_{2} \mathrm{O}_{3}-\mathrm{ZrO}_{2}$ thin films grown by reactive dual radio-frequency magnetron sputtering", Thin Solid Films 516 (2008) $4977-$ 4982.

[4] J.A. Wang, X. Bokhimi, A. Morales, O. Novaro, T. Lopez, R. Gomez, "Aluminum local environment and defects in the crystalline structure of sol-gel alumina catalyst", J. Phys. Chem. B. 103 (1999) 299- 303.

[5] R. L. Oréfice, W. L. Vasconcelos, "Sol-Gel Transition and Structural Evolution on Multicomponent Gels Derived from the AluminaSilica System" Journal of Sol-Gel Science and Technology 9 (1997) 239- 249.
Rh110 in sol-gel matrix. The scattering particle $\left(\mathrm{Al}_{2} \mathrm{O}_{3}\right.$ nanoparticles) has a huge role in both absorption and fluorescence intensities of Rh110 laser dye in case of the solution and the bulk samples.

[6] Y.K. Park, E.H. Tadd, M. Zubris, R. Tannenbaum, "Size-controlled synthesis of alumina nanoparticles from aluminum alkoxides", Materials Research Bulletin 40 (2005) 1506.

[7] S.V. Frolov, Z. Valy Vardeny, Anvar A. Zakhidov, Ray H. Baughman, "Laser-like emission in opal photonic crystals" Opt. Commun. 162 (1999) 241-246.

[8] S. Kragh, "A Solid State Micro Cavity Dye Laser-Design, Fabrication, and Characterization", MSc thesis, University of Copenhagen, Denmark (2003).

[9] V. Biju, M. Yamauchi and M. Ishikawa, "Distribution of Single Molecules in Polymer Thin Films", J. Photochem. Photobio. A: hemistry 140 (2001) 237- 241.

[10] W. Wang, X. Yang, Y. Fang, J. Ding, "Preparation and performance of form-stable polyethylene glycol/silicon dioxide composites as solid-liquid phase change materials", Applied Energy 86 (2009) 170- 174.

[11] W. Wang, Z. Zhang, G. Zu, J. Shen, L. Zou, Y. Lian, B. Liub and F. Zhangb "Trimethylethoxysilane- modified super 
MJPS, VOL.(4), NO.(1), 2017

heatresistant alumina aerogels for hightemperature thermal insulation and adsorption applications" RSC Adv., 4 (2014), 5486454871.

[12] X. Shi, C. Yang, L. Zhang, Z. Lu, Y. Zhu, D. Tang, C. Cui, and H. Zeng, "Mesoporous Alumina Microfibers In Situ Transformation from AACH Fibers and the Adsorption Performance", Journal of Nanomaterials (2014) 6 pages.
[13] S. Gong, et al., "Effect of water-aging on the antimicrobial activities of an ORMOSILcontaining orthodontic acrylic resin", Acta Biomaterialia, 4(2013), 6964-6973.

[14] X. Zhang, et al., "Fabrication of ridge waveguide structure from photosensitive $\mathrm{TiO}_{2}$ /ormosil hybrid films", Thin Solid Films, 531(2013) 119-124. 